Revista Iberoamericana, Vol. LXVIII, Núm. 199, Abril-Junio 2002, 253-268

\title{
LA FUNCIÓN DE “LOS AUTORES”: LA ADAPTACIÓN CINEMATOGRÁFICA TRANSNACIONAL DE EL LUGAR SIN LÍMITES
}

POR

\author{
CATHERINE GRANT \\ University of Kent
}

Arturo Ripstein, el director tiene quien le escriba ${ }^{1}$

A pesar de ser el auteur de la obra cinematográfica más original y distintiva en Latinoamérica desde finales de los años sesenta, el director mexicano Arturo Ripstein se ha centrado casi exclusivamente en la adaptación de obras literarias famosas de escritores de aquel continente. ${ }^{2}$ Antes de formar equipo en 1986 con su guionista actual, Paz Alicia Garciadiego, con motivo de la adaptación de El imperio de la fortuna, de Juan Rulfo, Ripstein había escrito sus guiones en colaboración con varios escritores latinoamericanos de primera fila. En 1978, estrenó su adaptación cinematográfica de la novela corta El lugar sin límites (1966) del escritor chileno José Donoso. La película, un melodrama sobre una familia queer, ubicado en un burdel-cabaret decrépito y que culmina con el asesinato homofóbico de su protagonista, artista drag, tuvo un gran impacto internacional. ${ }^{3} \mathrm{La}$ película eclipsó el éxito de la novela de Donoso, al tiempo que volvió a despertar el interés por el texto, que con anterioridad había circulado a nivel internacional como parte del

\footnotetext{
${ }^{1}$ Paranaguá, “Arturo Ripstein” 151. Me gustaría expresar mi agradecimiento a Laura Podalsky por sus sugerencias y por animarme a escribir este artículo, así como a su traductora, Irene Ruiz-Mora. ${ }^{2} \mathrm{Y}$ del otro lado del Atlántico también. Además Ripstein es conocido por unas cuantas remakes de películas antiguas mexicanas y de Hollywood, con guión de su colaboradora habitual desde 1986, Paz Alicia Garciadiego: como por ejemplo, La mujer del puerto (1991), Profundo carmesí (1996). ${ }^{3}$ La concisión de la siguiente sinopsis cinematográfica de El lugar sin límites es inmejorable: 'La Manuela, un homosexual que vive en el burdel pueblerino dirigido, de hecho, por su hija La Japonesita, teme el regreso del joven Pancho, con quien tuvo un altercado, y que vuelve en un camión por él comprado con el dinero que le prestó don Alejo, cacique del lugar. La acción retrocede al tiempo en que La Japonesa, madre de La Japonesita, concibió a ésta para ganar una apuesta de don Alejo: al cabo de una fiesta en el burdel, donde La Manuela baila disfrazado de mujer, logró que el homosexual copulara con ella. La acción vuelve al presente. Después de pagar su deuda con don Alejo, Pancho va con su cuñado Octavio al burdel de La Japonesita. Desde el gallinero donde se esconde, La Manuela ve como su hija es maltratada por Pancho. Esto le da el valor de aparecer vestido de andaluza y bailar ante Pancho "La leyenda del beso". En su actuación, La Manuela hace que Pancho baile con él y lo bese. Octavio ve eso y se lo reprocha a su cuñado. Furioso por haber sido sorprendido, Pancho persigue con Octavio por la calle a La Manuela y ambos hombres acaban matando a golpes al homosexual' (Pérez Estremera 128)
} 
boom literario latinoamericano. ${ }^{4}$ Aunque Ripstein fue el único que figuró en los créditos como guionista de El lugar sin límites, en el guión trabajó con Donoso (cuya novela aparece mencionada, por supuesto, como 'fuente' de la película), con el novelista, dramaturgo y guionista argentino Manuel Puig, así como con otros escritores mexicanos que no se mencionan en los créditos, como José Emilio Pacheco, Cristina Pacheco y Carlos Castañón. Puig y Ripstein mantuvieron una sonada disputa en torno a la contribución de Puig y el nombre de éste no aparece en los créditos. Mientras que todas las películas de Ripstein plantean aspectos interesantes sobre la autoría en colaboración, muy pocas lo hacen de manera tan llamativa como El lugar sin límites.

Muchos críticos y realizadores de cine no comercial en Latinoamérica — por ejemplo, el Grupo Cine Liberación y la formulación que hicieron a finales de los años sesenta de "Segundo Cine" en "Hacia un tercer cine" (Solanas y Getino)— han tachado el tipo de cine de auteur que Ripstein ha practicado durante cuatro décadas de ser "limitado ideológicamente”, “extranjerizante” o “eurocéntrico”, y “literario” o “individualista”. A pesar de estos ataques, es evidente que este modelo de producción cinematográfica (junto con la marca 'Ripstein') ha podido resistir frente a los avatares de carácter político, económico y cultural de los años setenta, ochenta y noventa en varios países del continente. Sin embargo, se han realizado pocos estudios exhaustivos en torno a este modelo como modo de producción con éxito a nivel internacional. En este artículo, pues, más que centrarme solamente en las semejanzas y diferencias entre la película homónima y los textos literarios (la principal actividad crítica en la que suelen embarcarse los estudios del proceso de adaptación), propongo utilizar la "historia” de la adaptación “transnacional” de El lugar sin límites, contada desde el punto de vista de sus diversos "autores” Donoso-Puig-Ripstein - para explorar algunas cuestiones referentes a la autoría en colaboración en la cultura cinematográfica y literaria en Latinoamérica después del final del período del boom literario. Mi intención no es ponderar las diferencias en las versiones que reproduzco aquí para descubrir una historia “verdadera," sino mostrar evidencias de que existe una diversidad en torno al discurso “de autor” sobre la adaptación de la novela de Donoso. Lo que es más, intentaré mostrar que el modo de práctica de una "adaptación de auteur" involucra necesariamente la contribución de colaboradores nombrados a la vez que requiere la “des-aparición” de éstos, hasta cierto punto. Mi argumento, tal y como el título sugiere, está basado en ciertos aspectos del concepto de Michel Foucault de "función del autor.” Para Foucault, la autoría supuestamente "individual” es el resultado de una operación compleja que construye cierto ‘ser de razón’ que llamamos “un autor” (Foucault 215). Según el crítico francés:

The author does not precede the works; he is a certain functional principle by which, in our culture, one limits, excludes, and chooses; in short, by which one impedes the free circulation, the free manipulation, the free composition, decomposition, and recomposition

\footnotetext{
${ }^{4}$ Como señala Suzanne Jill Levine, “'Movies made from novels prolong their sources' literary lives” (Levine, ix). La version cinematográfica de la novela de Donoso ha atraído la atención académica como película de culto gay así como texto "ripsteiniano" clave (véase de la Mora; y Paranaguá, Arturo Ripstein: el espiral de la identidad).
} 
of fiction. [...]The author is therefore the ideological figure by which one marks the manner in which we fear the proliferation of meaning (Foucault 221-21).

CRÓNICA DE UNA ADAPTACIÓN

El infierno son los otros ${ }^{5}$

Los tres principales colaboradores en la “autoría” de la adaptación cinematográfica de El lugar sin límites - Donoso, Puig y Ripstein - han dado sus versiones de lo que ocurrió durante este proceso (Donoso, La calle; Puig; Ripstein; Yakir; Levine, Entraigües; García Riera; Pérez Estremera). Tal y como señalan, y según los historiadores cinematográficos, parece ser que fue Luis Buñuel el que primero adquirió los derechos de la novela de Donoso a finales de los años sesenta, pero no pudo convencer a los censores en España, donde vivía entonces, para realizar la película (Millares; Monterde). Según Ripstein, su padre, Alfredo Ripstein, un conocido productor de películas comerciales mexicanas y amigo de Buñuel, adquirió entonces los derechos y dejó el proyecto en manos de su hijo (Entraigües 93). Ripstein Jr. entró en contacto con Donoso, que en aquella época vivía en México, ${ }^{6}$ y así comenzaron en serio los planes de adaptación en 1975.

A mitad de los años setenta, Ripstein ya se había consolidado como cineasta. Sus cinco primeros largometrajes, realizados a partir de 1965, habían sido financiados por el Estado y la mayoría de ellos fueron filmados en el prestigioso complejo cinematográfico estatal de Estudios Churubusco, muestra tanto del aprecio que se le tenía así como de los excelentes contactos que tenía en la industria cinematográfica como ayudante de Buñuel y como hijo de un productor notable. ${ }^{7}$ De hecho, esta misma trayectoria "prometedora" se había visto truncada a causa de la insatisfacción que Ripstein experimentó por el carácter “comercial” e "impersonal” de sus primeras películas. Tras una breve incursión experimental en el terreno del cine independiente y de bajo presupuesto (un cambio que coincidió con los acontecimientos políticos que sucedieron en México a partir de 1968), regresó al ámbito comercial en la primera parte de los años setenta con el deseo de utilizar sus películas como forma de expresión personal (y de principios). Este interés en el cine de autor lo puso en contacto con una generación de cineastas (Cazals, Leduc, Fons, Hermosillo, Isaac y otros), cuyas películas formarían el llamado “Nuevo Cine Mexicano”. Estos directores fueron inicialmente apoyados por el entonces director del Banco Nacional Cinematográfico, Rodolfo Echeverría, un tecnócrata interesado en fomentar un cine “de interés nacional y extraordinario”; sin embargo, con la llegada de su sucesora, Margarita López Portillo, dicho apoyo disminuyó. Con la crisis económica y política, y el descenso de público nacional e internacional de cine mexicano, la postura de Ripstein, cada vez más contestataria en la industria, lo llevó a obtener menor apoyo del Estado para su proyecto

\footnotetext{
${ }^{5}$ Paranaguá (siguiendo Huis clos de Sartre), Arturo Ripstein 132.

${ }^{6}$ Donoso había acabado de escribir la novela durante su estancia prolongada en la casa de Carlos Fuentes, en Ciudad de México (Millares 18).

${ }^{7}$ Los largometrajes anteriores son Tiempo de morir (1965), Los recuerdos del porvenir (1968), El castillo de la pureza (1972), El santo oficio (1973), Foxtrot (1975). Ripstein también había dirigido varios cortometrajes, documentales y proyectos para la televisión.
} 
de adaptación de la obra de Donoso El lugar sin límites, de temática homosexual y escenario un tanto sórdido. Mientras decidió rodar parte de la película en Querétaro, se vio obligado a trasladar el resto del rodaje de los Estudios Churubusco a los Estudios América, de menor equipamiento, y recibió financiación ya no de la primera compañía productora estatal de la época (Conacine) sino de la menos prestigiosa Conacite Dos (Monterde 467). ${ }^{8}$

A mediados de los años setenta, el novelista, cinéfilo y guionista9 ${ }^{9}$ Manuel Puig había establecido su residencia en la Ciudad de México, lejos de las luchas políticas de su país natal. También había encontrado un lugar entre los círculos literarios y culturales, como Donoso, a quien conoció allí y cuyo trabajo admiraba. Sin embargo, pronto se desligó de las “mafias culturales” mexicanas (Puig cit. por Levine 271), y se trasladó, también de forma temporal, a Nueva York, Río de Janeiro y París. Mientras estaba en México, acabó de escribir su novela El beso de la mujer araña, finalmente publicada en España por Seix Barral en 1976, aunque también trabajó sobre guiones de películas y obras de teatro inspiradas por los melodramas musicales de la "Edad de oro" del cine mexicano de los años cuarenta y cincuenta, especialmente los del tipo cabaretera (Levine 268). Desafortunadamente, ninguno de éstos llegó a producirse. Uno de los productores con quien Puig se asociaba en aquel entonces, Manuel Barbachano Ponce, fue quien presentó al novelista argentino a Ripstein en 1975. Ripstein mostró sus simpatías por la primera novela de Puig, La traición de Rita Hayworth y, a su debido tiempo, como señala Suzanne Jill Levine, Puig le dio una copia de El beso de la mujer araña, lo cual hizo más profunda su admiración por la obra del escritor argentino (Levine 286). En septiembre de 1976, Ripstein encargó a Puig escribir un guión para su adaptación de El lugar sin límites. Aunque tenía sus dudas en torno a la adaptación de libros ya existentes, Puig estaba intrigado con la novela de Donoso (Levine 286) y entregó una primera versión del guión a Ripstein dos meses más tarde. Basándose en varias entrevistas y su conocimiento de Puig, Levine da su versión de los acontecimientos que sucedieron después en su excelente biografía del escritor argentino. ${ }^{10}$ Vale la pena citar el siguiente pasaje:

For Manuel this was almost a rehearsal, though he didn't realize it then, for his contributions to the film version of Kiss of the Spider Woman - the challenge of bringing a believable, sympathetic queen to a wider audience. [...] Manuel was worried about what Ripstein would do with his script, but, as it turned out, Ripstein was in tune with Donoso's unmasking of macho stereotypes - he portrays Pancho as an angry, insecure stud, and benevolent Don Alejo is even more elderly in the film — and gave the grotesque whores and La Manuela the human depth with which Donoso had imbued them. Manuel

\footnotetext{
${ }^{8}$ A pesar de todo, la película consiguió cuatro Arieles, los premios oficiales patrocinados por el estado, así como varios premios de los festivales de cine de San Sebastián y Cartagena de Indias (Monterde).

${ }^{9}$ Puig se había formado en el Centro Sperimentale di Cinema, en Roma.

${ }^{10}$ Levine menciona la ayuda de Ripstein en la investigación de dicha biografía (Levine 430), y algunas de las opiniones del director mexicano están reflejadas en la cita. Asimismo, ella entrevistó a Donoso. Quisiera señalar que mi investigación para este artículo fue inspirada y facilitada por la biografía de Manuel Puig escrita por Levine. La autora también ha traducido al inglés la novela de Donoso El lugar sin límites, como Hell Has No Limits, 1972, 1995.
} 
feared mainly that Ripstein would turn the gay character into a caricature, while Ripstein felt that Manuel was trying to make La Manuela too exaggerated and Pancho too macho, and believed that his directorial interpretation of Donoso's feelings about machismo and sexual underdogs was more nuanced. As Manuel saw it, Ripstein's psychological realism and expressionist touches - mirrors, dark interiors - tried to reflect an inner life but were oppressive; his camera direction tended towards 'artsy' static tedium.

After the script was taken out of his hands and worked over by the Mexican writer José Emilio Pacheco, Manuel asked that his name be not included in the credits. Pacheco and Ripstein had agreed on making it clear to the spectator that Pancho kills La Manuela, whereas Manuel wanted to preserve the original's ambiguous ending - which left Manuela's fate to the reader's imagination, and also left open the possibility that Pancho's brutality would go unpunished.

Though the film was 'overdone, like an El Greco painting,' Manuel ultimately regretted withdrawing his name from the credits: 'I liked it, but I had taken my name off it, because of the threat of censorship. At that time, 1978, the Argentine drama was at its worst [the military had launched its golpe in March 1976], so I became hysterical. I was also censored in Spain and Hungary, so I was becoming paranoid. The film was a success' [Yakir: 208]. With the Mexican elections coming up, Manuel was concerned about possible censorship, especially, he implied, if a known homosexual signed a script in which the main character was gay. But Ripstein claims that Manuel feared he would deal with the transvestite in a crass manner. It was the same apprehension Manuel experienced later with Hector Babenco's, or, rather, William Hurt's, interpretation of Molina [in El beso de la mujer araña]. (Levine 286-87)

Volveré en breve al tema de la transfiguración que la adaptación cinematográfica hace de su fuente novelística; en su propia versión publicada de estos y otros acontecimientos referentes a su relación con el cine, ${ }^{11}$ Puig describe las cosas de una manera más “equilibrada,” al parecer casi “auto-censurándose”: ${ }^{12}$

From Mexico, Arturo Ripstein asked me to adapt José Donoso's novella El lugar sin límites. At first I said no, but Ripstein insisted, so I read the book again. It was more of a long short story than a novel, so in this case the problem was to add material to round out the script. This I enjoyed far more [than his earlier experience of 'compressing' his own novel Boquitas pintadas for Torre Nilsson's 1974 homonymous film], and my good working relationship with Ripstein led to another project, which I myself suggested: the adaptation of a story by the Argentine writer Silvina Ocampo, 'El impostor' [filmed as El otro, 1984, with Puig taking the screenwriting credit this time]. What did El lugar sin límites and 'El impostor' have in common? [...] Both stories were allegories, poetic in tone, without any claims to realism, even though basically they dealt with well-defined human problems. (Puig 287-88)

\footnotetext{
${ }^{11}$ Existe un prefacio especialmente escrito para una colección española de guiones (1985) para otras películas en las que colaboró Puig ("La cara del villano” y "Recuerdo de Tijuana”) publicados en Seix Barral, Barcelona. Este prefacio fue traducido al inglés como ‘Cinema and the Novel’ por Nick Caistor y fue incluido en Modern Latin American Fiction: A Survey, de John King.

${ }^{12}$ Como he dicho en la introducción, mi intención no es descubrir una historia "verdadera", sino mostrar evidencias de que existe una diversidad en torno al discurso "de autor” sobre la adaptación de la novela de Donoso.
} 
Pese a esta visión optimista referente a su experiencia como colaborador de Ripstein, Puig insinúa más adelante en el artículo que las películas contemporáneas de auteur como las que componen la obra del director mexicano, aunque no lo diga directamenteno están a la altura de las películas realizadas en la era clásica de los estudios tanto en Hollywood como en México (Puig 289).

Cabe la posibilidad de que Ripstein se reconciliara con Puig públicamente, si no lo había hecho del todo en privado, cuando decidió dirigir la versión teatral de El beso de la mujer araña, basada en el guión de Puig, que estuvo en cartel en la ciudad de México entre 1979 y 1981 (Levine 286). ${ }^{13}$ En cualquier caso, de nuevo aconteció una disputa entre ellos a causa del guión de Puig para El otro. Aún cuando los detalles de las declaraciones de Puig y Ripstein no coinciden en importancia, lo que está claro es que la amargura en torno a la adaptación de El lugar sin límites que desprende Ripstein está en consonancia con las intensas emociones que Puig expresa a su biógrafa. Lo que queda es una "lucha de discursos” sobre la autoría de la película años después de su estreno. En una entrevista publicada en 1996, seis años después de la muerte del escritor argentino en la Ciudad de México, Ripstein recuerda que, con motivo del estreno de El otro en $1984,{ }^{14}$

Puig después lanzó una diatriba furibunda en contra de la película por los cambios que le hice, misma diatriba que había hecho, pero al revés, cuando terminamos de hacer $E l$ lugar sin límites, película que no quiso firmar cuando la hicimos originalmente, pero que cuando vio los cambios hechos por mí y que la película tenía éxito, entonces el tipo sí se paró el cuello y dijo que él había hecho todo, cosa que era falsa. En ésta [El otro] fue exactamente lo contrario. Fue muy desagradable trabajar con Puig. (Ripstein 99)

En cuanto a la opinión de Donoso sobre la adaptación de su obra, Levine señala que "[he] felt pleased and honoured when he learned that Manuel had authored the screenplay of his novel, which dealt frankly with the taboo subject of homosexuality” (Levine 286). Donoso dio permiso a Ripstein para cambiar el final de la novela (Monterde 48), y para incrementar el grado de "esperpentismo” derivado “[d]el sentido tragicómico de la existencia mexicana”, según señala Lluis Miñaro Albero en su valoración de la película (Miñaro Albero 39). Y mientras que a Donoso le gustó la película en conjunto, en una entrevista publicada en 1979, apuntó:

La verdad es que la novela trata de cómo somos nosotros, los chilenos, un poco más grises, más sombríos, con menos colores, más matizados, más sutiles que los mexicanos (...) La transposición a México sacrificó nuestro lenguaje cotidiano hasta convertirlo en otro idioma (...) Es un libro sombrío. Otoñal, frío, lleno de corrientes de aire, de olor a orujo, con presencias de habitaciones vacías, cargadas de pobreza. La versión cinematográfica mexicana hizo que todo se llenara de cromatismo. Las prostitutas, por ejemplo, aparecen

\footnotetext{
${ }^{13}$ Gonzalo Vega (Pancho en El lugar sin límites) la protagonizó en el papel de Valentín.

${ }^{14}$ Curiosamente, en el momento de hacer la entrevista al menos, El otro fue una de las películas que menos le satisfizo: "Es una película que prefiero no discutir. Era pobre de producción, pobre de concepto, pobre de elementos, pobre de realización, pobre de imaginación, pobre técnicamente... Era una miseria” (Ripstein 99).
} 
vestidas de todos los colores, cosa que en Chile no pasaría (...) Se ha interpretado bien la letra de mi novela, pero no se captó su poesía. (Donoso, “José Donoso” 30)

¿Fueron los Pachecos y Castañón embarcados en el proyecto por Ripstein antes de que surgieran los “problemas con Puig” o con su guión, simplemente para ayudar en la "mexicanización” de Ripstein de la traducción original del autor argentino del escenario chileno y el idiolecto de Donoso? ¿O fueron embarcados después, para “corregir” el guión en otros niveles (Puig creía que éste era el caso, tal y como explica Levine), quizás para contribuir a los esfuerzos del propio Ripstein para "hacer su propia obra”? En mi opinión, es difícil tener clara alguna de estas dos posibilidades. ${ }^{15}$ Sin embargo, parece obvio que a causa de la eliminación del nombre de Puig de los créditos, el trabajo del director en el guión debió ser suficiente para justificar que sólo apareciera el nombre de Ripstein como guionista en los créditos y no el de los otros escritores mexicanos. En versiones posteriores de la película, por ejemplo en la carátula de la versión más reciente de vídeo, sí que se reconoce en los créditos a José Emilio Pacheco como co-guionista de Ripstein. Irónicamente, además, la página web oficial del Instituto de Cine Mexicano, que tiene su propia versión de los datos técnicos de la película, no señala el trabajo de los dos amigos mexicanos, sino que formaliza en los créditos la colaboración “transnacional” de Ripstein y Puig. ${ }^{16}$

TRANSPOSICIONES TRANSNACIONALES

... cada texto de Arturo Ripstein es un lugar sin límites ${ }^{17}$

Parece obvio, si miramos en retrospectiva, por qué a Ripstein le atrajo la novela de Donoso. Como indica Donoso parcialmente (y como en casi todas las demás películas de Ripstein hasta la fecha), El lugar sin límites trata temas como la pobreza, la miseria, la sexualidad humana poco convencional, familias queered (o deformadas) por el capitalismo patriarcal y otros temas políticos de interés en Latinoamérica, como el de la actual pervivencia del latifundismo y caciquismo neofeudales. ${ }^{18}$ Como ha señalado Ripstein sobre su interés en la adaptación de obras literarias de sus colegas latinoamericanos, "Más que el realismo mágico en cine, me interesa lo real atroz” (Entraigües 96). No obstante, si José Emilio Pacheco al final sí que participó en el proceso de escritura del guión, ¿por qué Ripstein le pidió a Manuel Puig que adaptara El lugar sin límites al principio, y no a su viejo y leal amigo, con quien ya había co-escrito cuatro largometrajes? ${ }^{19}$ Quizás

\footnotetext{
${ }^{15}$ Tengo que reconocer que no he podido acceder a una fuente importante que podría clarificar este asunto: Emilio García Riera, Arturo Ripstein habla de su cine con Emilio García Riera, 1988. A esta fuente hacen referencia constantemente los estudios mexicanos sobre la obra de Ripstein, aunque estos estudios no hacen apenas referencia a la colaboración de José Emilio Pacheco.

${ }^{16}$ Place Without Limits, 1998 versión VHS distribuida por World Artists Home Video. Esta página web puede encontrarse en http://www.imcine.gob.mx/lugar. html.

${ }^{17}$ Generelo Lanaspa 99.

${ }^{18}$ Sergio de la Mora se ha referido a este último punto en su excelente ensayo sobre esta película de Ripstein (De la Mora 91).

${ }^{19}$ Las películas fueron El castillo de la pureza (1972), El santo oficio (1973), Foxtrot (1975), y el documental El palacio negro (1976). Paulo Antonio Paranaguá considera a Pacheco como uno de
} 
Ripstein creyó que la autoría de Puig contribuiría con algún elemento "diferente” en su obra cinematográfica; o quizás pensaba que la novela de Donoso requería el talento especial de Puig para ser llevada al cine.

Voy a comentar brevemente la “contribución” más evidente que Puig pudo hacer en la adaptación: la de su experiencia homosexual “auténtica”. ${ }^{20}$ Aunque en las películas de Ripstein anteriores a El lugar sin límites (así como en los que le siguen) ya habían aparecido en diversas ocasiones los temas de la homosexualidad, la bisexualidad y la sexualidad ambigua, La Manuela es su primer y único protagonista loca. Como ya he comentado, la obra de Puig había impresionado tanto a Ripstein como a Donoso — dos heterosexuales convencidos y hombres casados - por la descripción (a menudo autobiográfica) de la homosexualidad en general, y de la "locura” en particular. Quizás se siguió en este caso el principio no siempre creíble de "it takes one to know one”. ${ }^{21}$ Aunque podría suponerse que el escritor argentino estaba limitado por sus propias experiencias "nacionales" de la identidad homosexual a la hora de "traducir" el personaje de La Manuela al contexto mexicano, yo diría que Puig, como gay "practicante” en la Ciudad de México entre 1972 y 1975, ya habría tenido conocimiento de primera mano de la vida y las costumbres homosexuales en México (véase Levine 245 y pássim). Parece evidente que Puig era consciente de su papel en este sentido en la adaptación, por la referencia que hace Levine al tortuoso periodo que siguió a la entrega de su guión de El lugar sin límites. Las preocupaciones de Puig por su seguridad como hombre gay reconocido conforme se aproximaba el estreno de la película en 1978 están justificadas, incluso habiendo otros factores que le hicieran eliminar su nombre de los créditos de la película.

Lo que también queda claro es que la contribución de Puig en la adaptación no apunta especificamente a su "nacionalidad” 0 , incluso, a su política, ${ }^{22}$ que quizás fue menos fácil de caracterizar que la visión compartida entre Donoso y Ripstein, anti-feudal, antineocolonial, pro-panlatinoamericanista, filtrada a través de sus propios lentes nacionales. Por supuesto, desde un punto de vista práctico, cada uno de los tres “autores" principales de El lugar sin límites —Donoso, Puig y Ripstein— habían acabado juntos en el melting pot cultural de la ciudad de México a causa de los caprichos del exilio forzoso durante la primera mitad de los años setenta. En este ambiente, en comparación con otros miembros de la élite literaria internacional (Fuentes, Paz, Rulfo, García Márquez y Pacheco, entre otros), el caché literario de Puig venía de su reputación como uno de los escritores de la nueva generación post-boom, con el escaparate del humor y de elementos de cultura pop(ular), la fusión de géneros narrativos múltiples y la capacidad de ser influido por una variedad de formas artísticas y culturales. Mientras Donoso comenzó su carrera como escritor del "boom” en un sentido bastante clásico o “genérico,” a partir de los años setenta vio cómo su obra se iba llenando de estos nuevos valores: en una entrevista en 1981, él se

los dos “interlocutores privilegiados" de Ripstein durante su carrera en el entorno literario mexicano; el otro sería el novelista Vicente Leñero (Paranaguá, Arturo Ripstein 181).

${ }^{20}$ Así lo han dado a entender varios especialistas, incluyendo a Levine y Sergio de la Mora, y muchas de las reseñas sobre la película. También se ha destacado la excelente interpretación de Roberto Cobo en el papel de La Manuela.

21 "Hay que llevarlo en la sangre para transmitirlo".

${ }^{22}$ Obviamente, dejo fuera la política sexual de Puig. 
describió a sí mismo como “literario, plástico y músico, por ese orden” (Donoso, Diario 16, 7). En este sentido, lo que resulta especialmente interesante de la obra de Donoso de 1966 es que, a pesar de sus cualidades como reescritura boom del regionalismo latinoamericano, también "personifica” lo que podría interpretarse como elementos llamativamente post-boom en su personaje central de loca, La Manuela, con su gusto por chismorrear, su humor cruel y su apego nostálgico a los populares boleros y cuplés, así como a la cultura híbrida del mundo de los espectáculos de los años cincuenta en Latinoamérica y Hollywood. Las novelas anteriores de Puig, que Ripstein conocía bien en el momento de encargarle el guión, rebosaban de personajes y diálogos similares, de estilo indirecto libre, y de referencias culturales parecidas. Como señala Lluis Miñaro Albero en su reseña sobre El lugar sin límites, "los personajes en el film parecen más criaturas del escritor argentino que del chileno" (Miñaro Albero 39).

Se ha llegado a decir que el guión sólo se “mexicanizó” cuando la versión de Puig llegó a las manos de Ripstein y sus otros colaboradores. Esto podría bien ser el caso en términos de diálogos. Como comenta de la Mora, basándose en su conocimiento de las conversaciones de García Riera con Ripstein, el diálogo “undergoes a triple transformation: from chilenismos to argentinismos to mexicanismos” (de la Mora 102). Sin embargo, lo que todavía no se ha reconocido suficientemente, en mi opinión, es que Puig estaba perfectamente preparado para contribuir en otros aspectos claves a la expansión "mexicanizada" de muchas de las referencias culturales originales de la novela de Donoso. ${ }^{23}$ Durante su estancia en México, no solamente se había convertido en experto en cine musical mexicano de los años cuarenta y los cincuenta (Levine 268), con sus boleros y mambos interpretados dentro de la diégesis, sino que también se había visto inmerso en la cultura ranchera mexicana, tanto en la música norteña como en la tradición cinematográfica del charro. Entre 1974 y 1975 incluso escribió un musical para la famosa cantante de rancheras Lucha Villa (Levine 270). Villa también era venerada por Ripstein, quien la eligió para el papel de La Japonesa Grande en su película.

En la novela de Donoso se hace referencia a las letras de cuatro piezas de música popular, bien reproduciéndolas, bien aludiendo a las mismas: se trata de tres boleros, "Vereda tropical” (Donoso, El lugar sin límites 112), "Bésame mucho” (Donoso 146) y "Flores negras” (Donoso 168) y de un pasodoble español o cuplé, "El relicario," que siempre acompaña el baile de fiestas de La Manuela (Donoso 168). En la adaptación cinematográfica, los boleros que se utilizan son totalmente diferentes, así como la música de tradición cubana (son y mambo) y la tradición ranchera mexicana, en su mayor parte con versiones grabadas por conocidos músicos mexicanos o afincados en México (Pepe Arévalo y sus Mulatos, las Hermanas Gómez y Hernández, Sonora Santanera, entre otros).

\footnotetext{
${ }^{23}$ De la Mora parece suponer que Ripstein era el responsable de la selección musical: "the use of music helps to locate the film in a Mexican cultural context. Ripstein uses classic modern Mexican music for the soundtrack” (de la Mora 102). De hecho, la música de la película no es ni más ni menos "mexicana" que la que aparece mencionada en la novela. La mayor parte de la música en ambos textos es de producción cubana o influida por ésta y algo de música española. Solamente las dos rancheras que hay en la película (de las doce piezas de música que encontramos en la película en conjunto) son mexicanas "en sentido puro" — formas musicales tradicionales mexicanas escritas e interpretadas por músicos mexicanos.
} 
Estas canciones y piezas musicales no tienen la función primordial de resaltar la acción de la película. Al igual que las canciones principales y los bailes típicos en las películas del subgénero de la cabaretera de los años cuarenta y cincuenta, la música en El lugar sin límites muchas veces aparece de manera destacada. Es más, se representa claramente su fuente diegética en cada ocasión en que se oye (la radio, el wurlitzer o el tocadiscos, o la representación en directo). La música de la película también tiene una clara función formal y narrativa. Como Carlos Monsiváis ha señalado, los boleros de cabaretera ayudan a establecer el espacio del burdel o cabaret como "a moral hell and sensorial heaven, where the 'forbidden’ was normalised” (Monsiváis, "Mythologies” 118). Tanto en la sección central de la estructura tripartita ${ }^{24}$ de la película, en la que la acción retrocede al México de los años cincuenta (no sólo la "Edad de Oro” del cine sino también la “edad de oro” del tipo de burdel y ciudad retratados en El lugar sin límites), como en el resto de la película, la selección (y mise-en-scène) de la música recuerda a propósito la tradición cinematográfica anterior, al tiempo que señala lo anacrónico e inapropiado de aquellas mitologías para unos personajes de los años setenta: los personajes apenas interpretan las canciones ellos mismos, sino que escuchan y de vez en cuando imitan la música reciclada. El lugar sin límites fue la primera de las películas de Ripstein que no tuvo una banda sonora especialmente compuesta para la misma y aunque muchos de sus trabajos anteriores utilizan música diegética, lo hacen de manera esporádica. Después de 1978, la mayoría de las películas de Ripstein siguieron utilizando música diegética de diversos tipos y no grabada para la ocasión (desde boleros prestados a fragmentos de ópera) al estilo de los que colaboraron en la adaptación del texto de Donoso.

Solamente "El relicario" permanece en la transposición de la novela al cine. Aun así, su función como clímax en la novela de Donoso es reemplazada en la película por la incorporación de otra pieza musical tomada de la tradición española del cuplé. Como explica Levine, éste es uno de los aspectos de la película que Ripstein ha reconocido como contribución exclusiva de Puig. En las entrevistas con la biógrafa de Puig, Ripstein admite que:

the best moment of the film was written by Manuel: the fatal dance that poor Manuela, decked out in a red feathery flamenco dress outlining his bony male buttocks, performs for Pancho. La Manuela dances to a wordless Spanish song [sic $]^{25}$ ([performed] by Los Churumbeles de España) titled 'La Leyenda del Beso', [...] based on the myth of the sleeping princess awakened by a prince's kiss. Manuel added the words and inverted the myth: this time the sleeper is a young man [Pancho] awakened to his sexuality by a woman’s kiss [La Manuela]. La Manuela's dance for Pancho, aggressively seductive, precipitates disaster: when brother-in-law Octavio sees Pancho swept away to the point of kissing La Manuela, Pancho is obliged to defend his masculinity by beating $\mathrm{La}$ Manuela to death. (Levine 287-88)

${ }^{24}$ Esta estructura está más claramente delineada en la película que en la novela, en la que los recuerdos de los personajes exceden los límites de los capítulos que tratan de la llegada de La Manuela al burdel y de la concepción de La Japonesita.

${ }^{25}$ No se trata de una wordless song sino de música sin acompañamiento vocal del "Intermedio" de los actos segundo y final de la zarzuela u opereta española La leyenda del beso, compuesta por R. Soutullo y J. Vert, estrenada por primera vez en Madrid en 1924. El argumento de la ópera no tiene 
Solamente una canción que se ha asociado sistemáticamente con Ripstein a lo largo de su carrera, "Perfume de Gardenias”, ${ }^{26}$ aparece en la película. Además, parece que se invoca literalmente como una melodía de sello “ripsteiniano,” ya que se escucha dos veces: la primera, durante la película en una grabación de Sonora Santanera y la segunda, al final, durante los títulos de crédito, con un arreglo instrumental de la misma canción. En este caso, y dado que Ripstein nunca antes había utilizado la música como lo hace en esta ocasión, podría especularse que Puig jugó un papel más significativo en la selección musical de lo que se podría haber pensado. El autor argentino era, al fin y al cabo, la persona responsable en un principio de "extender" el escenario original de la novela: podemos percibir esta extensión de manera más obvia en el incremento de "números" musicales (de cuatro a doce canciones) y en su mayor protagonismo.

Lo que es más, tendría que argüir que el estilo de bricolage musical de la película apunta tanto o más la autoría a Puig que a Ripstein. ${ }^{27}$ Como Lucille Kerr escribe en un estupendo capítulo sobre Pubis angelical, de Puig (ubicada en México a mitad de los años setenta), esta novela, como la obra de Puig en general "seems to eradicate traditional authorial indicators with the forms of discourse and narration through which its story [...] is told. But it also figures authorial interests and aims” (Kerr 93). Según Kerr:

when one thinks of Puig's writing one thinks of the themes and forms of detective fiction or serial fiction, popular songs, soap operas and Hollywood movies, as well as of the languages of fashion magazines, psychoanalysis and melodrama, among others -all juxtaposed and combined to shape Puig's literary signature. The figure to which one would give the name Puig thus surfaces through certain topics, talk and techniques that have been regarded as characteristic of his writing - as constitutive of his style. (Kerr 103-04)

Kerr sostiene que, hasta cierto punto, Puig “des-aparece” como autor:

\begin{abstract}
He presents himself [in this and other novels] as a virtual compiler who combines and correlates discourses that originate with no individual subject [...]. Puig disappears as an author [from the discourse of his novels] also because he works through a mode of writing that is grounded in the virtual stealing of the styles of others [...]. Oddly, though his work derives from the cultural models that belong not to any individual author but rather to contemporary culture itself, those models have nonetheless come to mark Puig's position as a writer of original texts. (Kerr 105-06)
\end{abstract}

\footnotetext{
demasiado en común con la historia de El lugar sin límites, pero se puede apreciar alguna conexión interesante. Las he tratado en profundidad en dos trabajos de investigación sobre el cine de Ripstein (Grant, “Music and Performance” y “Entertainment and Dystopia”). En cualquier caso, la adaptación que Puig realiza de la música de esta operetta indica cierto conocimiento de su fuente narrativa. ${ }^{26}$ Paranaguá señala que "Perfume de gardenias" es "una de las campeonas del hit-parade de Ripstein”, ya que aparece en varias de sus películas (Paranaguá 30).

${ }^{27}$ No obstante, es bien conocido el interés musical de Ripstein en seleccionar la música con sus guionistas en casi todas las películas siguientes, si bien últimamente su guionista habitual y compañera sentimental, Paz Alicia Garciadiego, ha tomado la responsabilidad en este terreno. Asimismo ha dirigido varias óperas tanto dentro como fuera de México.
} 
Obviamente, algunas de las palabras de Kerr tienen cierta resonancia en este artículo porque El lugar sin límites es una película de cuyos créditos desaparece oficialmente el nombre de Puig. No obstante, la caracterización que Kerr hace de Puig en su capítulo como "copier, as well as an editor, of the scripts of others (perhaps, one might even say, as a kind of scriptor)” (Kerr 105) también es pertinente porque el escritor argentino construye sobre (y también parte de) préstamos líricos, aunque muy limitados, del propio Donoso en su novela. Puig "adapta," de manera muy productiva, los "guiones” preexistentes y hasta cierto punto anónimos que proporcionan las canciones de la música popular y la cultura cinematográfica. Estas grabaciones e interpretaciones no sólo “acompañan” a la película, como ya habían hecho en alguna ocasión en las primeras películas de Ripstein: son utilizadas, tal y como Puig usa las letras de canciones en sus novelas, para contar la historia. Estos pequeños “mitos” en su forma musical local, aunque también “universal," ofrecen a El lugar sin límites, como Monsiváis escribe acerca del bolero, "songs that make intimate history a public concern - the autobiography of everyone and no one” (Monsiváis, "Bolero: A History” 312). Ésta, por tanto, es una elección de carácter ético, y un asunto que atañe tanto al estilo del autor como al “contenido” narrativo de la película.

EN NOMBRE DE “RIPSTEIN”

El lugar sin límites es, de alguna manera, una película que me da patente de seriedad ... me doctora en esos términos, me doctora.

En 1978, la adaptación de El lugar sin límites ganó el premio al mejor guión en el Festival de Cine de San Sebastián. Irónicamente, el premio lo recogió Arturo Ripstein, sólo uno de los que estuvieron involucrados en la redacción del guión de la película, aunque acompañado de varios de sus protagonistas. Desde el principio, pues, la película fue acogida como una producción de auteur. Aunque estuvo basada, originalmente, en las palabras e ideas de otras personas, y, como en todas las películas comerciales, fue fruto de la colaboración activa de diversos artistas y técnicos, institucionalmente y por su modo de circulación, ésta fue una película de Ripstein. Donoso fue el autor de la novela y Puig el scriptor de la película; sin embargo, sólo ‘Ripstein’ apareció como autor de la película.

Lo que he intentado hacer en mi investigación, hasta este momento, es similar a lo que Robert Carringer ha descrito como la actividad de la primera de las dos fases en el análisis de la autoría en colaboración. Esta primera fase 'entails the temporary suspension of single author primacy [...] to appraise constituent claims to a text's authorship. In the second phase, the primary author is reinscribed within what is now established as an institutional context of authorship' (Carringer 377). Ya he destacado que Ripstein no sólo consiguió el material original para su adaptación de José Donoso y Manuel Puig. A través de su colaboración con estos autores también consiguió un tipo de historia y un acercamiento al estilo que llegaría a caracterizar su cine a partir de ese período. Las narrativas de sus películas continuarían dedicándose a hacer referencia, directa o indirectamente, a la "Edad de Oro” del cine melodramático de su país y quizás también a la de políticos de la época 
para desvelar las deficiencias de ambas instituciones desde aquel período, en medio del neo-colonialismo. En cuanto a los flash backs estilísticos, también seguirían llenando su paleta cinematográfica con los valores utópicos de las formas populares musicales y cinematográficas. Parafraseando la inteligente consideración de Lucille Kerr en torno al estilo de Puig como autor (Kerr 105-06), y aplicándolo a Ripstein, después de El lugar sin límites, este tipo de préstamos situaron el nombre de “Ripstein” como autor responsable de una empresa que enmarcaría de manera crítica formas culturales tradicionalmente situadas fuera del "arte culto", pero resituadas por su proyecto como auteur. Además, el estatus de los modelos "populares", cuyo estilo "roba" la película, se modifica para que se adhiera a los principios normalmente identificados con el estilo "culto". Y lo "culto" es de alguna manera transformado por el contacto con lo que inicialmente parece ser “popular”. Esos modelos se transfieren como propiedad de "Ripstein”, bajo cuyo nombre son recibidos y re-autorizados: los otros autores “desaparecen”. Quizás por esto, a pesar del relativo estatismo de la cámara en El lugar sin límites, muy diferente del estilo más fluido que caracterizó sus trabajos posteriores, muchos críticos e historiadores cinematográficos —y también el propio Ripstein — consideran esta película como la primera intervención seria de "Ripstein" como auteur cinematográfico. ${ }^{28}$

Aunque la historia de Donoso resultó “mexicanizada” por la película de Ripstein, no se convirtió solamente en una "historia mexicana"; Cien años de soledad tampoco fue recibida (fuera de Colombia, al menos), como una "historia colombiana”. El proceso de adaptación transnacional de una novela del "boom” latinoamericano permitió a Ripstein desarrollar un estilo y distinción internacionales. ${ }^{29}$ Pero esto lo consiguió no solamente al decidir adaptar una obra literaria que ya se había distribuido internacionalmente. ${ }^{30}$ Como sostiene Paulo Antonio Paranaguá, otros directores mexicanos del "Nuevo Cine

\footnotetext{
${ }^{28}$ Esta opinión aparece, por ejemplo, en el exhaustivo estudio de José Enrique Monterde (1996) en torno a la trayectoria de Ripstein anterior a El lugar sin límites (Monterde 46-9). Véase también Generelo Lanaspa (100-01). Arturo Ripstein está de acuerdo con esta afirmación en la correspondencia publicada en 1995, a la cual pertenece el epígrafe que abre esta sección (Pérez Estremera 170). Curiosamente, en la misma correspondencia, Ripstein vuelve a afirmar su insatisfacción con los primeros cuarenta minutos de la película (ya lo había hecho en sus entrevistas con García Riera en 1988). Sostiene que esta sección se torna débil en el diálogo, que intenta dar a entender demasiada información sobre el "pasado" de los personajes, sin dejar esta labor al sonido o imágenes, que podrían “contarlo” de modo más cinematográfico (Monterde 56, 170). ¿ ¿ Se atuvo Ripstein demasiado al guión de Puig, cargado de diálogos, para su gusto posterior?

${ }^{29}$ Aquí parafraseo las palabras de Marvin D’Lugo en su destacado estudio sobre la autoría y el cine nacional (D’Lugo 339): propone la misma idea en referencia al director español Carlos Saura. Estoy en deuda con su interpretación de la "función del autor" en el cine nacional. He realizado dos investigaciones sobre la distribución internacional contemporánea y los contextos del marketing del auteurism cinematográfico (Grant, "www.auteur.com” y "Recognizing Billy Budd in Beau Travail”). $\mathrm{El}$ "estilo internacional” de El lugar sin límites obviamente tuvo que reconocer, no obstante, los contextos nacionales e internacionales de financiación, regulación y distribución que definían el cine mexicano en aquella época.

${ }^{30}$ Ripstein ha seguido adaptando obras de autores del boom y post-boom latinoamericano, así como de otros escritores post-coloniales (por ejemplo, la novela Principio y fin, de Naguib Mahfuz, estrenada en 1993).
} 
Mexicano" también trataron de adaptar este tipo de obras (Paranaguá 39), al ver los patrocinadores gubernamentales que el prestigio de las obras originales se contagiaba a su cine nacional. Ripstein asumió un riesgo adicional en El lugar sin límites que funcionó bastante bien. Aunque siempre había trabajado dentro de los límites de la censura nacional, ${ }^{31}$ Ripstein, sin embargo, en esta ocasión utilizó a un escritor conocido por su retrato "posmoderno" de la homosexualidad — las novelas de Puig ya se habían vendido por miles en varias lenguas en todo el mundo. Y situó un protagonista loca en el centro de su encuadre cinematográfico. La película tuvo el éxito en el circuito de festivales internacionales que cualquier cineasta mexicano hubiera soñado; el tema central de su película le aseguró un lugar destacado y duradero más allá de este circuito como película de "culto" (Paranaguá 125): el que "hablaba” con su convincente retrato de la homosexualidad a una comunidad de público gay emergente a nivel nacional e internacional.

Si Arturo Ripstein se benefició del éxito estético y crítico de su película, yo diría que su película también funcionó para promover la obra de otros autores/colaboradores. Mientras Donoso pudo no quedar satisfecho con la transposición de la película, su novela siguió imprimiéndose a lo largo de su vida y todavía se publica en varias lenguas, a diferencia de otras obras suyas que en un principio tuvieron más éxito que El lugar sin límites. Puig también salió beneficiado de su asociación con el éxito de la película de modo directo e indirecto. Aunque su nombre fue suprimido oficialmente a petición propia de los títulos de crédito de la película de Ripstein, hay que decir que se ha escrito bastante sobre su contribución — que en su mayoría ha venido del propio Puig — lo cual asegura que su nombre se asocie siempre con El lugar sin límites como “el autor des-aparecido”. Mientras tanto, la segunda película distribuida a nivel internacional desde las Américas con un protagonista loca fue otra adaptación cinematográfica transnacional: The Kiss of the Spider Woman (1985), dirigida por Héctor Babenco, y de nuevo con el guión de Puig basado en su propia novela. Y el autor argentino siempre consideró que esta película le proporcionaría la “entrada a la inmortalidad” (Levine ix).

Traducido por Irene Ruiz-Mora

\footnotetext{
${ }^{31}$ La posibilidad de un plano con desnudo frontal de La Manuela emergiendo del río, que podría sugerir la novela de Donoso (Donoso, El lugar sin límites 168) fue rechazada para la película; y además, el diálogo de la película no se refiere al tamaño de su pene como lo hace la novela. La película sí incluye un atrevido plano de la entrepierna (con ropa) de Pancho, conforme La Japonesita le mete mano (una escena que no aparece en la novela), aunque esto ocurre muy brevemente en un contexto heterosexual (véase de la Mora 92-7).
} 
Carringer, Robert. “Collaboration and Concepts of Authorship”. PMLA 116/2 (March 2001): 370-79.

D’Lugo, Marvin. "Authorship and the Concept of National Cinema in Spain”. The Construction of Authorship: Textual Appropriation in Law and Literature. Martha Woodmansee y Peter Jaszi, eds. Durham/Londres: Duke University Press, 1994. 327-42.

Donoso, José. El lugar sin límites. Selena Millares, ed. Madrid: Cátedra, 1999. Hell Has No Limits. [1979]. Suzanne Jill Levine, trad. Copenhagen/Los Angeles: Green Integer Books, 1995. (entrevista) “José Donoso. En un mundo de imágenes”. La calle (20 de marzo de

1979): 49. Cit. Selena Millares, “Introducción”. José Donoso, El lugar sin límites. Selena Millares, ed. Madrid: Cátedra, 1999. 9-91. (entrevista). Diario 16 (15 de enero de 1981): 7.

Entraigües, Jimmy. "Encuentro en el suspiro del melodrama las herramientas que más me gustan para definir mis películas”. Entrevista [con Arturo Ripstein]. El cine de Arturo Ripstein: La solución del bárbaro. Banda Aparte Imágenes 2. Jesús Rodrigo García, ed. Valencia: Ediciones de la Mirada, 1998. 91-97.

Foucault, Michel. "What is an author?” Josué V. Harari, trad. Aesthetics, Method, Epistemology. James D. Faubion, ed. Londres: Penguin, 1998. 205-22.

García Riera, Emilio. Arturo Ripstein habla de su cine con Emilio García Riera. Colección Testimonios del Cine Mexicano, 1. Guadalajara: Centro de Investigación y Enseñanza Cinematográficas, Universidad de Guadalajara, 1988.

Generelo Lanaspa, Jesús. “El lugar sin límites: México del revés”. El cine de Arturo Ripstein: La solución del bárbaro. Banda Aparte Imágenes 2. Jesús Rodrigo García, ed. Valencia: Ediciones de la Mirada, 1998. 99-108.

Grant, Catherine. "Music and Performance in 'Old' and 'New' Mexican Melodramas”. Unpublished paper. Film Studies Symposium: "Re-Generating Genre”. University of Kent, June 15, 1999.

"Entertainment and Dystopia: Music and Performance in El lugar sin límites". Unpublished paper. Film Studies Research Seminar. University of Kent, November 29, 2000.

“www.auteur.com.” Screen 41/1 (2000): 101-08.

"Recognizing Billy Budd in Beau Travail: epistemology and hermeneutics of an auteurist ‘free' adaptation”. Screen 43 (forthcoming 2002).

Kerr, Lucille. Reclaiming the Author: Figures and Fictions from Spanish America. Durham/Londres: Duke University Press, 1992.

Levine, Suzanne Jill. Manuel Puig and the Spider Woman: His Life and Fictions. Londres: Faber, 2000.

Millares, Selena. “Introducción”. José Donoso, El lugar sin límites. Selena Millares, ed. Madrid: Cátedra, 1999. 9-91.

Miñaro Albero, Lluis. “El lugar sin límites”, Dirigido Por 62 (1979): 38-39. 
Monsiváis, Carlos. “Mythologies”. Ana M. López, trad. Mexican Cinema. Paulo Antonio Paranaguá, ed. Londres: British Film Institute, 1995. 117-27.

Monsiváis, Carlos. “Bolero: A History”. Mexican Postcards. John Kraniauskas, ed. y trad. Londres: Verso, 1997. 270-318.

Monterde, José Enrique. “De la Inquisición a 'la Manuela””. Nosferatu 22 (septiembre 1996): 40-49.

de la Mora, Sergio. "Fascinating Machismo: Towards an Unmasking of Heterosexual Masculinity in Arturo Ripstein's El lugar sin límites”. Journal of Film and Video 44/ 3-4 (Fall-Winter 1992-1993): 83-104.

Paranaguá, Paulo Antonio. “Arturo Ripstein: el director tiene quien le escriba”. La mujer del puerto de Arturo Ripstein. Revista Viridiana 14 (enero 1997): 151-67. Arturo Ripstein: el espiral de la identidad. Madrid: Cátedra, 1997.

Pérez Estremera, Manuel. Correspondencia inacabada con Arturo Ripstein. Huesca: Festival de Cine de Huesca, 1995.

Puig, Manuel. "Cinema and the Novel”. Modern Latin American Fiction: A Survey. Nick Caistor, trad. y John King, ed. Londres: Faber, 1987. 283-90.

Ripstein, Arturo. “Entrevista”. Nosferatu 22 (septiembre 1996): 81-109.

Solanas, Fernando y Octavio Getino. "Towards a Third Cinema: Notes and Experiences for the Development of a Cinema of Liberation in the Third World". New Latin American Cinema. Volume One: Theory, Practices, and Transcontinental Articulations. Michael Chanan, trad. y Michael Martin, ed. Detroit: Wayne State University Press, 1997. 33-58.

Yakir, Daniel. “Kiss of the Spiderwoman: Manuel Puig”. Interview (September 1985): 208. Cit. Suzanne Jill Levine, Manuel Puig and the Spider Woman: His Life and Fictions. Londres: Faber, 2000. 